\title{
Editorial: Synergistic Effects of Pervasive Stressors on Ecosystems and Biodiversity
}

\author{
Brenda C. McComb ${ }^{1 *}$ and Samuel A. Cushman ${ }^{2}$ \\ ${ }^{1}$ Oregon State University, Corvallis, OR, United States, ${ }^{2}$ United States Forest Service (USDA), Flagstaff, Arizona, AZ, \\ United States
}

Keywords: land cover, climate change, fire disturbance, biodiversity conservation, ecological scaling

\section{Editorial on the Research Topic}

\section{Synergistic Effects of Pervasive Stressors on Ecosystems and Biodiversity}

Society is facing global threats to ecosystem function and conservation of biodiversity as a result of synergistic interactions of pervasive stressors such as climate change, invasive species proliferation, land use/land management, and other perturbations (Chapin and Diaz, 2020). The likely effects of these stressors taken in isolation are often well-known, but their impacts on ecosystems and societies are uncertain because the interactions among the drivers of change are poorly understood (Chapin and Diaz, 2020). These stressors have been known for decades and their effects on ecosystems have been studied, but only recently have the synergistic effects of multiple stressors been considered. As global change continues to accelerate, leading to increases in the extent and severity of these stressors, it is likely that they will increasingly interact in ways that non-linearly

OPEN ACCESS

Edited and reviewed by: Orsolya Valkó,

Hungarian Academy of Science, Hungary

*Correspondence: Brenda C. McComb brenda.mccomb@oregonstate.edu

Specialty section: This article was submitted to Conservation and Restoration Ecology,

a section of the journal Frontiers in Ecology and Evolution

Received: 05 June 2020

Accepted: 21 October 2020

Published: 06 November 2020

Citation:

McComb BC and Cushman SA (2020)

Editorial: Synergistic Effects of

Pervasive Stressors on Ecosystems and Biodiversity.

Front. Ecol. Evol. 8:569997. doi: 10.3389/fevo.2020.569997 increase adverse impacts on ecosystems.

The effects of these stressors, both individually and synergistically, may be mitigated or exacerbated by local, regional, national, or global policies and agreements. In recent years, abrupt changes in policies by states and nations have eroded collective and cooperative action in regulating and mitigating many of these stressors. This has reduced our ability to limit increases of individual stressors (such as climate change and deforestation), and has increased the likelihood of greater negative synergies among multiple stressors in their effects on ecosystems and populations. Thus, our ability to conserve biodiversity in the face of these interacting stressors is in greater doubt. The rapid change in policies, and resulting acceleration of land use change, climate change, altered disturbance regimes, spread of invasive species, and spread of pollutants may give rise to novel ecosystem structures and functions. For example, climate change will require large range shifts by many species. Simultaneously, altered disturbance regimes, increasing anthropogenic landscape change, and invasive species spread degrade the suitability of existing conditions to support many populations, and impose barriers that block migration and movement of populations from current to potential future suitable conditions. The interaction of these several factors may create severe negative synergies where populations cannot persist where they currently are, but cannot migrate to where they may be able to persist in the future. Therefore, we can no longer assess effects of these and other stressors one at a time, but rather we must consider synergies among them. However, we are only beginning to see efforts at providing quantitative estimates of such synergistic effects of stressors (e.g., the Stress Addition Model; Liess et al., 2016).

The series of papers included in this Research Topic were selected to illustrate how multiple stressors synergistically influence ecosystem structure and function. We highlight some of the findings produced from these papers as examples of the kinds of information needed to address policy change at a variety of scales of space and time to mitigate synergistic effects on populations, 
ecosystem functions and ecological processes. In addition, papers included in this series allow us to begin to understand how synergistic stressors might influence future ecosystem structure and function, which will influence our ability to conserve biodiversity. Finally, this series of papers provide conceptualizations of the effects of multiple stressors within and among ecosystems over multiple spatial and temporal scales, while considering the uncertainty associated with fluxes in each of the stressors.

\section{SCALING ECOLOGICAL RESILIENCE}

One key to understanding the synergistic effects of multiple stressors is to recognize that effects are scale dependent. Changes in climate are giving rise to changes in fire frequency, intensity and size, especially in many forested landscapes of the western U.S. The response of biotic systems to these changes can differ depending on changes in any of these characteristics of fire regimes, and the underlying mechanisms that drive system response to the new disturbance regimes. Falk et al. describe the effects of climate change on altering disturbance regimes and ecosystem resilience. They propose a model that scales resilience across space, time, and levels of biological organization, and illustrate how mechanisms of persistence, recovery, and reorganization are scale-dependent. Their model has the potential to facilitate integration of resilience ecology into future policy decisions that influence management and ecosystem restoration following unprecedented disturbances. Restoration ecologists often identify reference sites, “... which represent environments that are as close to the historical condition as can be attained in today's world (Egan and Howell, 2005)." Falk et al. point out that identifying reference conditions can be problematic because it is increasingly difficult to find systems that have not been degraded in some way simply because of pervasive and synergistic ecosystem stressors. Further, they point out that historical communities or species distributions typical of reference conditions may not be optimally adaptive under conditions of rapid change. Given these rapid changes, ecological resilience must be understood in a spatiallydependent, dynamic context to ensure that responses are adaptive to new conditions and not simply an effort to restore a past condition that may not be sustainable or even attainable. Indeed, Falk et al. raise the possibility of an ".... increasing probability of massive reorganization of forest ecosystems on a scale that has not been previously observed for thousands of years." But conclude with advice that, “... applying a scaling framework to post-disturbance ecological response can identify key mechanisms that will help ecosystems adapt to a rapidly changing and stressful world."

\section{COMBINED EFFECTS OF MULTIPLE STRESSORS: NEW INSIGHTS INTO THE INFLUENCE OF TIMING AND SEQUENCE}

Although the rate of change of broad-scale ecosystem and disturbance processes, such as wildfire, can be rapid and extensive, issues of scale also come into play in other systems and sometimes at small spatial scales and over short time frames. Nonetheless, hypotheses associated with synergistic stressors have rarely been tested in formal experiments. Brooks and Crowe conducted a manipulative field experiment to test independent and synergistic effects of two stressors (Copper and Biocide) on marine epifauna. The effects that they documented confirm that the two stressors acting together produce effects that are not predictable based on their independent influences. First, time-lags between stressors led to longer-lasting effects. In addition, the order in which the two stressors were introduced influenced the effects that they observed. The metal first sequence showed effects on community respiration, while the biocide first sequence produced effects on clearance rates. Based on their findings, future research should incorporate which combinations, sequences and time lags of stressors will have specific impacts on ecosystem structures and functions. This type of information could allow managers to make decisions regarding the sequence of exposure to multiple stressors to reduce net negative impacts on certain states and processes. Most importantly, their results suggest sensitive dependence not only to which stressors occur but also on the sequence and duration of each stressor. This suggests that synergistic effects of multiple stressors may have key attributes of complex systems that make extrapolation based on stationary assumptions of effects difficult, and suggest research on multiple stressors must incorporate conceptual and analytical frameworks to detect, measure and predict these complex interactions.

\section{SYNERGISTIC EFFECTS OF CLIMATE AND LAND-COVER CHANGE ON LONG-TERM BIRD POPULATION TRENDS OF THE WESTERN USA: A TEST OF MODELED PREDICTIONS}

Rosenberg et al. (2019) reported a net loss approaching 3 billion birds (29\% decline) since 1970 in North America, and suggested that interacting stressors, complicated by climate change, are likely drivers of these changes. Betts et al. developed models to predict declines in 110 species of birds in the western U.S. from 1983 to 2010. They found that 45 species significantly declined over the 27-year period but only 8 species increased in abundance. This clearly demonstrates a large decline in avian biodiversity at the sub-continental scale. Climate change alone best predicted trends for 44/108 species, while land-cover changes alone best predicted trends for $47 / 108$ species. A model combining the synergistic effects of these two drivers of population change best predicted trends in 59/108 species. Including information on land-cover change increased prediction success over climate data alone for 37 species. These results illustrate that the combination of multiple stressors is the most common driver of the observed declines in broad-scale avian diversity. Models, such as those produced by Betts et al. can help to predict the species most likely to be at risk from the synergistic effects of climate change and land-use change. They caution, however, that land use change may play a more 
prominent role in associations with bird population declines in areas where there have been more rapid and profound changes in land use than in the areas they included in their work.

\section{RECENT AND PROJECTED FUTURE WILDFIRE TRENDS ACROSS THE RANGES OF THREE SPOTTED OWL SUBSPECIES UNDER CLIMATE CHANGE}

Wan et al. explored how climate-induced changes in wildfire characteristics were likely to influence a federally threatened species, the spotted owl (Strix occidentalis). Projecting predicted changes in fire extent across ecosections of the western United States under climate change scenarios (Littell et al., 2018) onto the ranges of the three spotted owl subspecies, Wan et al. found that the proportion of area burned will increase within the ranges of all three subspecies under climate change, but the extent of that increase will vary among subspecies and among ecoregions within each subspecies. Their results also suggest differential vulnerability of the three spotted owl subspecies to synergistic interactions with other threats. For example, while Wan et al. found that predicted area burned by wildfire will likely increase greatly in both the Mexican and northern spotted owl ranges, the implications of these changes are dramatically different for the two subspecies. First, the effects of wildfire on spotted owl habitat depend substantially on the proportion and extent of high severity fire (Jones et al., 2016; Wan et al., 2020). Second, Wan et al. show that, whereas the majority of fire in the Mexican spotted owl range is expected to burn at low intensity, a large majority of fire in northern spotted owl range will be high severity, leading to an impactful synergy between increasing area burned, fire severity and loss of owl habitat. Furthermore, the northern spotted owl is particularly at risk from other past and ongoing stressors, such as extensive harvest of their preferred old-growth forest habitat, coupled with competition from the invasive barred owl (Strix varia), which together greatly reduce territory occupancy and productivity. The synergy, therefore, of potentially massive increases in high severity fire in the context of preexisting stressors suggests that the effects of climate driven changes in fire regime will be much more severe for the northern spotted owl than the other subspecies, even if the projection of total change in amount of fire is similar between them. The combination of increased climate-driven fire extent and risk of high-severity fire suggests a potential for large-scale future loss or modification of spotted owl habitat, particularly for the northern spotted owl subspecies. As pointed out by Falk et al., the resilience of these forests following fires is scale dependent, and in the case of spotted owls the recovery time to return to suitable habitat, if it occurs, will represent many generations of owls. Wan et al. recommend conducting further studies to understand the interaction and synergistic effects of climate change and wildfire on the spotted owl. Further, because environmental stressors such as wildfires, climate change, and barred owl invasion can interact, future studies should focus on the synergistic effects of these stressors on each subspecies.

\section{OUT OF THE ASHES: ECOLOGICAL RESILIENCE TO EXTREME WILDFIRE, PRESCRIBED BURNS, AND INDIGENOUS BURNING IN ECOSYSTEMS}

Keeping with the theme of ecological resilience to predicted larger and more intense fires driven, in part, by climate change, Eisenberg et al. describe the response of an aspen (Populus tremuloides) parkland-prairie system to both prescribed fire and a wildfire of significant size and intensity. The wildfire did not change aspen-cover extent or cause non-native grass eruption, but it reduced native-grass diversity and produced more pronounced shifts in ecosystem structure and biodiversity than the prescribed burn. Prescribed burns occurred in late spring, with little fuel available, while the wildfire occurred in late summer, with abundant fuel-amplifying the difference in severity. Past prescribed burn treatments did not mitigate the severity of the wildfire. This important result suggests that to be effective at altering an ecosystem state, prescribed fire may need to be implemented under conditions producing higher intensity fires and over larger spatial extents. Future prescribed burns in this system could be applied in the late season, which would be more consistent with Traditional Ecological Knowledge (TEK) leading to systems that are more resilient to fire and pervasive stressors such as invasive plants, although TEK approaches may need to be adapted to future conditions that will be quite different from the past. Collectively, the results of this paper show that prescribed fire as traditionally practiced in this system neither influences ecosystem or community structure the same as natural fire, nor alters and reduces fire risk, as desired by managers, and that a spatially and temporally modified treatment regime will be required to achieve desired ecosystem conditions.

\section{MOVING BEYOND SILOS IN CUMULATIVE EFFECTS ASSESSMENT}

Hodgson et al. propose five priorities for addressing the challenges of understanding how synergistic effects might be seen in ecosystems in the future within the conceptual framework of cumulative effects analyses. First, they suggest adopting risk-based approaches that account for uncertainty in our understanding and establishing an underlying theory for when we expect certain impacts to occur. Second, they note the importance of developing heuristics that identify attributes of organisms, populations, ecosystems, and stressors that lead to certain types of impacts. Third, they emphasize the critical need to develop a defined subdiscipline focused on cumulative effects, to help reduce the silos of research that are often disconnected. Fourth, as part of this effort of transcending disciplinary silos, the urge the development of a common set of definitions and methods, and fifth consistent use openly available data.

Hodgson et al. suggest that these priorities are intended to improve the use and application of science in decisionmaking, while also fostering more rapid conceptual advances. We believe that addressing the often complex, multi-scale influences of multiple interacting stressors will require transformation of 
traditional disciplinary research. No research group or even research field has the conceptual or methodological expertise to fully address synergistic effects of multiple ecological stressors. Therefore, integrating methods and ideas from multiple fields into analysis of risk and impacts is essential.

\section{CONCLUSIONS}

Several themes emerged from the papers in this series. First, systems are resilient to many types of disturbances and stressors, but how ecosystem resilience is manifested is dependent on spatial and temporal scales over which the stressor occurred, the order in which stressors are applied, and the interactions among stressors, leading to a high level of uncertainty in system responses. Second, synergies are apparent when examined in comparison to the independent effects of stressors. Betts et al. showed an increased effect on bird declines with the joint effects of climate change and land use. Brooks and Crowe demonstrated synergistic effects in a controlled experiment, but further demonstrated that the order in which a stress is applied matters. Third, the effects of climate on other stressors, especially fire, was a consistent theme in many of the papers in this series. The synergistic interaction of climate-driven changes in fire regimes with other stressors may differ dramatically for different populations of the same species (Wan et al.), but are predictable based on the specific changes in fire regime (area burned vs. severity) and how that interacts with other limiting factors and stressors (e.g., habitat loss from logging and competition from an invasive competitor, in the context of spotted owls). Additional work should be focused on synergies between climate and a wide variety of other stressors such as land use, fire, current management strategies, and many others. Fourth, reference sites as a means of understanding changes

\section{REFERENCES}

Chapin, F.S. III., and Diaz, S. (2020). Interactions between changing climate and biodiversity: shaping humanity's future. Proc. Natl. Acad. Sci. U.S.A. 117, 6295-6296. doi: 10.1073/pnas.2001686117

Cote, I.M., Darling, E. S., and Brown, C. J. (2016). Interactions among ecosystem stressors and their importance in conservation. Proc. R. Soc. B 283:20152592. doi: $10.1098 /$ rspb.2015.2592

Egan, D., and Howell, E. A. (eds.). (2005). The Historical Ecology Handbook: A Restorationist's Guide to Reference Ecosystems. Science \& Practice of Ecological Restoration. Washington, DC: Island Press.

Jones, G. M., Gutiérrez, R. J., Tempel, D. J., Whitmore, S. A., Berigan, W. J., and Peery, M. Z. (2016). Megafires: an emerging threat to old- forest species. Front. Ecol. Environ. 14, 300-306. doi: 10.1002/fee.1298

Liess, M., Folt, K., Knillmann, S., Schafer, R. B., and Liess, H. D. (2016). Predicting the synergy of multiple stress effects. Sci. Rep. 6:32965. doi: 10.1038/srep32965

Littell, J. S., McKenzie, D., Wan, H. Y., and Cushman, S. A. (2018). Climate change and future wildfire in the Western United States: an ecological approach to nonstationarity. Earth's Future 6, 1097-1111. doi: 10.1029/2018EF000878 in ecosystem structure and function resulting from synergistic effects of stressors become more difficult to find and justify. Furthermore, the key concept of desired ecological conditions, that underpins the adaptive management paradigm of Federal land management in the United States, must be developed, assessed and modified in the context of the interactions of multiple interacting stressors and changing system conditions. Climate change is a global stressor. Past ecosystems were different from those that will emerge in the future, and we must understand how changing climate, interacting with land use, altered fire regimes, and other perturbations influence the reorganization of ecological systems. Fifth, we need to consider how best to advance knowledge on synergistic effects of stressors on ecosystem functions in order to provide information to policy makes and managers. Hodgson et al. provide recommendations for advancing cumulative effects research to achieve that goal, including forming an "interdisciplinary discipline" to ensure that currently siloed disciplines work together. Finally, we end this overview of the Research Topic with a quote that pertains to the results of all of the studies in this series:

"Pending a general framework for predicting interactions, conservation management should enact interventions that are robust to uncertainty in interaction type and that continue to bolster biological resilience in a stressful world," (Cote et al., 2016).

\section{AUTHOR CONTRIBUTIONS}

This editorial was prepared equally by BM and SC.

\section{ACKNOWLEDGMENTS}

We thank the authors who contributed to this special topic.

Rosenberg, K. V., Dokter, A. M., Blancher, P. J., Sauer, J. R. Smith, A. C., Smith, P. A., et al. (2019). Decline of the North American avifauna. Science 366, 120-124. doi: 10.1126/science.aa w1313

Wan, H. Y., Cushman, S. A., and Ganey, J. L. (2020). The effect of scale in quantifying fire impacts on species habitats. Fire Ecol. 16:9. doi: 10.1186/s42408-0200068-2

Conflict of Interest: The authors declare that the research was conducted in the absence of any commercial or financial relationships that could be construed as a potential conflict of interest.

Copyright (c) 2020 McComb and Cushman. This is an open-access article distributed under the terms of the Creative Commons Attribution License (CC BY). The use, distribution or reproduction in other forums is permitted, provided the original author(s) and the copyright owner(s) are credited and that the original publication in this journal is cited, in accordance with accepted academic practice. No use, distribution or reproduction is permitted which does not comply with these terms. 